\title{
GaSb Solar Cells Grown on GaAs Using Interfacial Misfit Arrays for use in the III-Sb Multi-junction Cell
}

\author{
George T. Nelson, ${ }^{1}$ Bor-Chau Juang, ${ }^{2}$ Michael A. Slocum, ${ }^{1}$ Zachary S. Bittner, ${ }^{1}$ Ramesh B. Laghumavarapu, ${ }^{2}$ \\ Diana L. Huffaker, ${ }^{2}$ and Seth M. Hubbard ${ }^{1, \text { a) }}$ \\ 1) Rochester Institute of Technology, Rochester, New York 14623, USA \\ ${ }^{2)}$ University of California, Los Angeles, Los Angeles, California 90095, USA
}

(Dated: November 21, 2017)

\begin{abstract}
Growth of $\mathrm{GaSb}$ with low threading dislocation density directly on GaAs may be possible with the strategic strain relaxation of interfacial misfit arrays. This creates an opportunity for a multi-junction solar cell with access to a wide range of well-developed direct bandgap materials. Multi-junction cells with a single layer of $\mathrm{GaSb} / \mathrm{GaAs}$ interfacial misfit arrays could achieve higher efficiency than state-of-the-art inverted metamorphic multi-junction cells while forgoing the need for costly compositionally graded buffer layers. To develop this technology, GaSb single junction cells were grown via molecular beam epitaxy on both GaSb and GaAs substrates to compare homoepitaxial and heteroepitaxial GaSb device results. The GaSb-on-GaSb cell had an AM1.5g efficiency of 5.5\% and a 44-sun AM1.5d efficiency of $8.9 \%$. The GaSb-on-GaAs cell was $1.0 \%$ efficient under AM1.5g and $4.5 \%$ at 44 suns. The lower performance of the heteroepitaxial cell was due to low minority carrier Shockley-Read-Hall lifetimes and bulk shunting caused by defects related to the mismatched growth. A physics-based device simulator was used to create an inverted triple-junction $\mathrm{GaInP} / \mathrm{GaAs} / \mathrm{GaSb}$ model. The model predicted that, with current GaSb-on-GaAs material quality, the not-current-matched, proof-of-concept cell would provide $0.5 \%$ absolute efficiency gain over a tandem GaInP/GaAs cell at 1 sun and $2.5 \%$ gain at 44 suns, indicating that the effectiveness of the GaSb junction was a function of concentration.
\end{abstract}

The state-of-the-art single-substrate multi-junction solar cell is the inverted metamorphic (IMM) cell, where lattice mismatched subcells are grown monolithically via compositionally graded buffer layers. ${ }^{1-3}$ Growth of a typical triple-junction (3-J) IMM starts with a GaAs (lattice constant $5.65 \AA$ ) substrate and lattice-matched GaInP $(1.8 \mathrm{eV})$ and GaAs $(1.4 \mathrm{eV})$ top and middle cells, and, because a well-developed lattice-matched bottom cell is not available, a several micron-thick transparent metamorphic buffer is grown to grade the lattice constant to 1.0-eV $\operatorname{In}_{0.3} \mathrm{Ga}_{0.7} \mathrm{As}(5.77 \AA){ }^{1,2}$ The buffer is typically a stepped sequence of $\mathrm{Ga}_{x} \operatorname{In}_{1-x} \mathrm{P}$ and results in full relaxation of the compressive stress via conditions that enable dislocations to glide to the wafer edges. ${ }^{4}$ However, not all threading dislocations can be eliminated as threading dislocation densities (TDD) of $5 \times 10^{6} \mathrm{~cm}^{-2}$ in the post-grade InGaAs are reported. ${ }^{5,6}$ The inversion of the growth limits the effects of these remaining threading dislocations on the top subcells. In 2013, Sharp Corporation reported an efficiency of $37.7 \%$ under air mass 1.5 global (AM1.5g) with the 3-J IMM approach. ${ }^{2}$

An alternative to the high efficiency IMM multijunction cell is the III-Sb multi-junction with interfacial misfit (IMF) arrays. The IMF growth technique enables growth of III-Sb materials directly on GaAs or Si without the need for a step graded buffer. ${ }^{7,8}$ When compared to the IMM cell, the III-Sb IMF multi-junction cell has two significant advantages. One is, as mentioned, the foregoing of the growth-intensive and costly metamorphic grade in favor of an IMF monolayer. In 2013, Woodhouse et al. found that the metamorphic buffer of a dual

a)Electronic mail: smhsps@rit.edu junction $\mathrm{Si} / \mathrm{GaAsP}$ IMM cell accounted for $\sim 29 \%$ of the capital expenditure of the cell. ${ }^{9}$ The second advantage is the wide range of well developed direct bandgap materials that are lattice matched to GaSb. This bandgap range begins at $0.3 \mathrm{eV}$ with $\mathrm{In} \mathrm{AsSb}$ and extends up to $1.3 \mathrm{eV}$ with AlGaAsSb. With the GaAs and GaSb lattice constants, therefore, the combined direct bandgap range available is roughly $0.3 \mathrm{eV}$ to $1.9 \mathrm{eV}$. This presents a straightforward path to cells with 4,5 , or more junctions with only a single IMF layer required. The IMM cell, in contrast, will require one or more additional graded buffers for additional junctions.

Without the IMF technique, the high degree of strain $(7.8 \%)$ caused by growth of a III-Sb material such as $\mathrm{GaSb}$ on GaAs results in strain relief in the form of misfit dislocations that cause $60^{\circ}$ threading dislocations to propagate through the active region of the device. However, with IMF array, nearly all strain $(98.7 \%$ for GaSb-on-GaAs) is strategically relieved by a sequence of $90^{\circ}$ Lomer dislocations. ${ }^{10}$. IMF technology has been used in the past to grow InGaAsSb photodetectors on $\mathrm{GaAs}^{11}$ and has recently seen interest for photovoltaic applications. ${ }^{12,13}$ As a first step, an inverted GaInP/GaAs/AlGaSb IMF 3-J solar cell was modeled by Synopsys Sentaurus TCAD. With known GaSb material parameters, ${ }^{14}$ the cell was simulated to be $38.7 \%$ efficient under AM1.5g illumination. Initial work has focused on a simpler single-junction (1-J) cell to evaluate the impact of the IMF on device properties.

Homoepitaxial and IMF 1-J $n-i-p$ GaSb cells were grown on p-type 2" GaSb (001) and GaAs (001) substrates via MBE using a Veeco Gen 930 solid-source reactor. Control cells were grown homoepitaxially on GaSb substrates, while IMF cells were grown on GaAs via IMF 

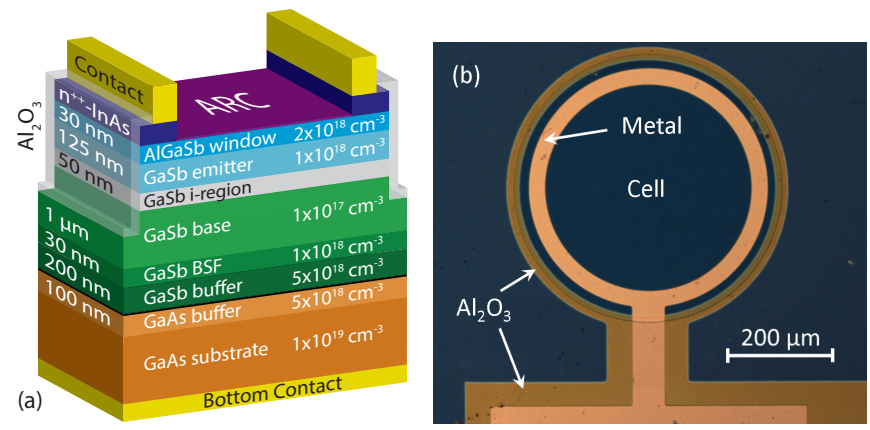

Figure 1. (a) Layer structure of the IMF cell and (b) microscope image of sidewall-passivated GaSb cells.

growth technique. ${ }^{15}$ For the IMF cells, a GaAs buffer layer was first grown on the p-type GaAs substrate with a growth temperature of $580^{\circ} \mathrm{C}$. A growth pause lead to As desorption and a Ga-rich surface, observed by a change in the reflection high-energy electron diffraction (RHEED) pattern from $(2 \times 4)$ to $(4 \times 2)$, followed by application of $\mathrm{Sb}_{2}$ overpressure changing the RHEED pattern to $(2 \times 8)$. The substrate was cooled to $510^{\circ} \mathrm{C}$ prior to GaSb growth. A GaSb buffer layer and the device layers were grown with $\mathrm{V} / \mathrm{III}$ beam equivalent pressure of 6 . Be and Te were used respectively for $\mathrm{p}$ - and n-type dopants. Doping densities were confirmed using Hall effect measurements on calibration samples grown on semi-insulating GaAs.

The fabricated IMF cell structure in Figure 1 depicts layers grown along with thickness and doping values. The control cell was grown identical to the IMF device, but on a GaSb substrate and without the GaAs buffer and IMF procedure. Strained $\mathrm{Al}_{0.3} \mathrm{Ga}_{0.7} \mathrm{Sb}(1.0 \mathrm{eV})$ was grown as the front window material, but a back window was eschewed in favor of a GaSb back surface field (BSF) layer to prevent strain in the base and emitter. InAs was chosen for the contact layer as it could be highly doped and a selective wet etch against $(\mathrm{Al}) \mathrm{GaSb}$ was available. A thin i-region was added to prevent interdiffusion between dopants at the junction by dopant diffusion. Cell design targeted efficiency of IMF cells under concentration and was guided by Sentaurus simulations using diffusion lengths extracted from early IMF cells. The n-i-p polarity was chosen because this would match a standard IMM polarity and high mobility of majority electrons in the emitter reduces series resistance which is important for high concentration. The optimal $n-i-p$ IMF cell was simulated with a $125 \mathrm{~nm}$-thick emitter and a 1 um-thick base. While not optically thick, lower IMF diffusion lengths prohibited a thicker cell. The thin design was kept for the homoepitaxial cell to maintain a comparison between cells.

Fabrication procedure was identical on IMF and homoepitaxial cells. A citric acid $/ \mathrm{HF} / \mathrm{H}_{2} \mathrm{O}_{2}$ solution was used to etch device mesas and contact layers. A sidewall passivation scheme known to work for GaSb-based infrared detectors was adapted to replace the sidewall oxide with $\mathrm{Al}_{2} \mathrm{O}_{3} \cdot{ }^{16}$ Before passivation, the native ox-

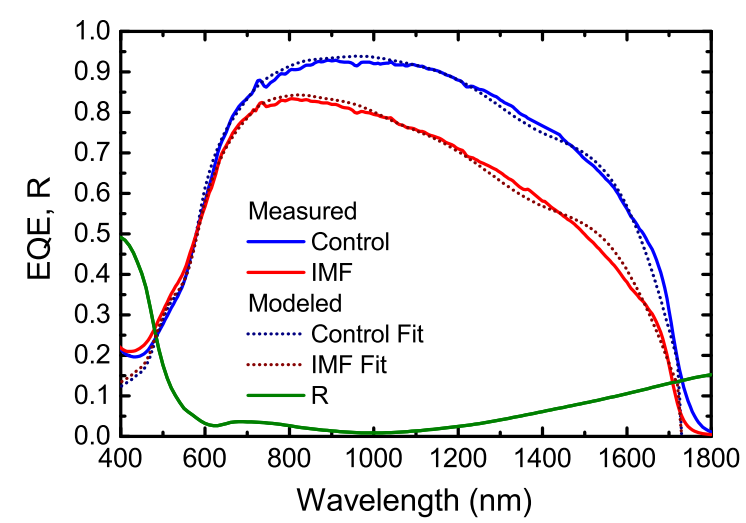

Figure 2. Measured EQE of homoepitaxial (control) and IMF cells (solid lines). Simulated EQE (dotted) and reflectance $(\mathrm{R})$ of the control and IMF with fitted lifetimes.

Table I. Parameters used for the GaSb 1-J simulations.

\begin{tabular}{lr}
\hline \hline Parameter & Value \\
\hline Bandgap, $E_{G}(300 \mathrm{~K})$ & $0.73 \mathrm{eV}$ \\
Electron mobility, $\mu_{e}\left(N=10^{17} \mathrm{~cm}^{-3}\right)$ & $3500 \mathrm{~cm}^{2} / \mathrm{V} \cdot \mathrm{s}$ \\
Electron mobility, $\mu_{e}\left(N=10^{18} \mathrm{~cm}^{-3}\right)$ & $1500 \mathrm{~cm}^{2} / \mathrm{V} \cdot \mathrm{s}$ \\
Hole mobility, $\mu_{h}\left(N=10^{17} \mathrm{~cm}^{-3}\right)$ & $500 \mathrm{~cm}^{2} / \mathrm{V} \cdot \mathrm{s}$ \\
Hole mobility, $\mu_{h}\left(N=10^{18} \mathrm{~cm}^{-3}\right)$ & $230 \mathrm{~cm}^{2} / \mathrm{V} \cdot \mathrm{s}$ \\
$\tau_{e, S R H}$ Control fit & $0.90 \mathrm{~ns}$ \\
$\tau_{h, S R H}$ Control fit & $2.5 \mathrm{~ns}$ \\
$\tau_{e, S R H}$ IMF fit & $0.040 \mathrm{~ns}$ \\
$\tau_{h, S R H}$ IMF fit & $0.070 \mathrm{~ns}$ \\
Radiative recombination coeff., $B_{\text {opt }}$ & $8.5 \times 10^{-11} \mathrm{~cm}^{3} / \mathrm{s}$ \\
Auger coefficient, $C_{A u g e r}$ & $5 \times 10^{-30} \mathrm{~cm}^{6} / \mathrm{s}$ \\
GaSb/AlGaSb interface recomb. vel. & $200 \mathrm{~cm} / \mathrm{s}$ \\
Series resistance, $R_{S}$ & $10 \mathrm{~m} \Omega \cdot \mathrm{cm}^{2}$ \\
\hline \hline
\end{tabular}

ide was removed using 1:1 $\mathrm{HCl}: \mathrm{H}_{2} 0^{17}$ and transferred to a 2nd generation Cambridge Nanotech Savannah atomic layer deposition (ALD) reactor. A 100-nm-thick layer of $\mathrm{Al}_{2} \mathrm{O}_{3}$ was deposited on the entire sample at $150^{\circ} \mathrm{C}$. The passivation layer was then patterned with photoresist and etched in 50:1 $\mathrm{H}_{2} \mathrm{O}: \mathrm{HF}$ solution to leave $\mathrm{Al}_{2} \mathrm{O}_{3}$ only on the sidewalls. An evaporated metal stack of $\mathrm{Pt} / \mathrm{Ti} / \mathrm{Au}$ was used for the back contact while $\mathrm{Ti} / \mathrm{Au}$ formed the front-metal grid. Finally, a two-layer anti-reflective coating (ARC) of $\mathrm{MgF}_{2}$ and $\mathrm{ZnS}$ was deposited.

The spectral response (SR) was measured with a Newport IQE-200 Quantum Efficiency Measurement System. Due to the small size of the cells, only relative SR could be taken by overfilling the cells. The lamp was calibrated using Si and Ge reference cells which received a portion of the light via a dichroic beamsplitter. The absolute SR was determined by scaling until the AM1.5g integrated current was equal to the calibrated $\mathrm{J}_{\mathrm{SC}}$ (see $\mathrm{I}-\mathrm{V}$ results below). The EQE (external quantum efficiency) of homoepitaxial and IMF cells (Figure 2) was fit with Sentaurus to extract Shockley-Read-Hall (SRH) 

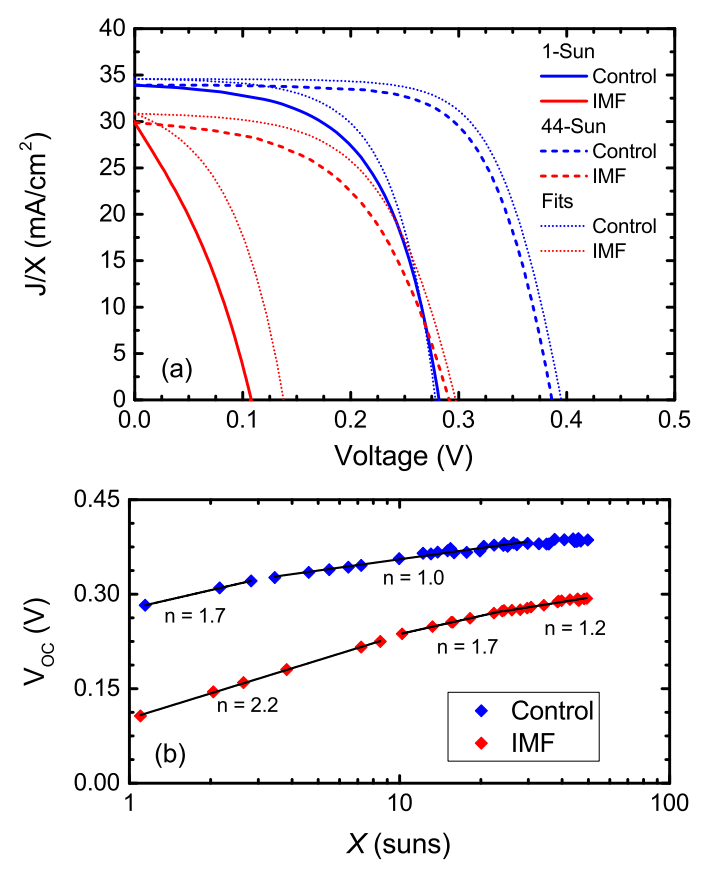

Figure 3. (a) AM1.5 illuminated I-V results at 1 sun (global) and 44 suns (direct, normalized to 1-sun global) for measured and simulated cells with the same lifetimes used in the EQE fit. (b) Measured open-circuit voltages under increasing concentration from 1 to 50 suns for the homoepitaxial and IMF cells with fit lines labeled by ideality factor.

lifetimes $\left(\tau_{S R H}\right)$ and minority carrier diffusion lengths (MCDL). The SRH lifetimes were assumed to be independent of doping, ${ }^{14}$ but MCDLs followed a doping dependence through the radiative component. The radiative recombination coefficient and other GaSb simulation parameters (Table I) were sourced from literature, ${ }^{14,18}$ except for mobilities, which were based on Hall effect measurements of calibration samples. To improve the fit accuracy, especially for the control cell which had diffusion lengths longer than the cell thickness, the MCDL values were recursively fit against the current-voltage (I$\mathrm{V})$ results discussed below. The fit MCDL of holes in the control cell emitter was $1 \mu \mathrm{m}$, while the MCDL of electrons in the base was $3 \mu \mathrm{m}$. For comparison, parameters from Sulima et al. predict MCDL of holes at the doping level of the emitter to be $4 \mu \mathrm{m}$ and MCDL in the base to be $12 \mu \mathrm{m} .{ }^{18}$ The fitted control MCDLs represent minimums rather than exact values as sidewall recombination (discussed later) was not explicitly accounted for in the simulation and thus the true 'bulk' diffusion lengths were longer. For the IMF, a good fit was achieved with MCDL of $0.2 \mu \mathrm{m}$ and $0.6 \mu \mathrm{m}$ for emitter and base, respectively. The reduced MCDLs in the IMF compared to the homoepitaxial cell correlated well to reduced photoluminescence intensity from IMF samples and is indicative of carrier loss from non-radiative recombination due to defects related to the IMF growth.

A Kiethley Source Meter 2440-C was used to measure
$\mathrm{I}-\mathrm{V}$ of devices. Illuminated I-V data were taken with a TSS Space Systems two-zone solar simulator calibrated to the AM1.5g spectrum using GaInP and Ge reference cells. The simulator was equipped with an AM1.5 filter and concentrating optics capable of increasing the power density to 50 suns AM1.5 direct (AM1.5d). A liquidcooled, temperature-controlled brass stage was used to hold the samples at $23^{\circ} \mathrm{C}$. For concentration measurements, the number of suns, $X$, was determined by dividing the $X$-sun short-circuit current $\left(\mathrm{J}_{\mathrm{SC}}\right)$ by the AM1.5d 1-sun $\mathrm{J}_{\mathrm{SC}}$. The AM1.5d 1-sun $\mathrm{J}_{\mathrm{SC}}$ was itself calculated from the $\mathrm{SR}$ and the AM1.5g $\mathrm{J}_{\mathrm{SC}}$. The concentrating optics consisted of an acrylic fresnel lens and a fused-silica condensing lens and care was taken to not re-image the light sources. The concentrated spectrum was not measured but the acrylic lens was expected to absorb only a minor amount of infrared light. As well, grid shading was over $18 \%$ and this was not factored out of current densities. Optimizing the grid shading is a straightforward route to increased current in future cells.

The I-V results are shown in Figure 3(a) and tabulated cell metrics are in Table II. Under AM1.5g, the $\mathrm{GaSb}$ control cell was $5.5 \%$ efficient, with a fill factor (FF) of $59 \%$, an open-circuit voltage $\left(\mathrm{V}_{\mathrm{OC}}\right)$ of $280 \mathrm{mV}$, and a short-circuit current $\left(\mathrm{J}_{\mathrm{SC}}\right)$ of $33.9 \mathrm{~mA} / \mathrm{cm}^{2}$. The metrics improved to $8.9 \%$ efficiency, $68 \% \mathrm{FF}$, and $386 \mathrm{mV}$ $\mathrm{V}_{\mathrm{OC}}$ under 44-sun direct spectrum. The simulated I-V data for the control device, produced by the same twodimensional Sentaurus model as the EQE simulations, was in satisfactory agreement with the measured data. While the simulation tended to overestimate $\mathrm{J}_{\mathrm{SC}}$ and FF it matched well with $\mathrm{V}_{\mathrm{OC}}$. The experimental results compare favorably to reported MBE-grown homoepitaxial GaSb photovoltaic cells because of improvements to sidewall shunt resistance (discussed below) and higher current collection due to the ARC. ${ }^{12,13,19}$

The IMF cell under AM1.5g was $1.0 \%$ efficient, with a FF of $33 \%, \mathrm{~V}_{\mathrm{OC}}$ of $108 \mathrm{mV}$, and a $\mathrm{J}_{\mathrm{SC}}$ of $29.9 \mathrm{~mA} / \mathrm{cm}^{2}$. Under concentration, the IMF cell had better relative recovery than the control. At 44 suns direct, the IMF cell efficiency improved to $4.5 \%$, the $\mathrm{FF}$ to $52 \%$, and the $\mathrm{V}_{\mathrm{OC}}$ to $291 \mathrm{mV}$. The simulated data from the IMF model at 1 sun overestimated the $\mathrm{V}_{\mathrm{OC}}$ and $\mathrm{FF}$ compared to experimental data due to the bulk shunt in the IMF, which could not be replicated easily in the model. At 44 suns direct, the effect of the shunt was reduced as the shunt path was saturated and this caused the fit accuracy to improve. The authors previously reported an IMF cell efficiency of $0.7 \%$, surpassed here due to greater current collection likely caused by a thin emitter better suited for the shorter IMF diffusion lengths as well as addition of the ARC. ${ }^{13}$ Despite the optimized cell thickness, the $\mathrm{V}_{\mathrm{OC}}$ of the IMF was low relative to the control and this was further evidence of IMF-related defects.

In Figure 3(b), $\mathrm{V}_{\mathrm{OC}}$ was measured as a function of concentration from 1-sun to 50-sun AM1.5d. Ideality factors were extracted from the fit lines. The ideality factor of the control changed from 1.7 (depletion region recombi- 
Table II. Homoepitaxial and IMF 1-J measured solar cell metrics.

\begin{tabular}{|c|c|c|c|c|c|}
\hline Cell & Spectrum & $\mathrm{J}_{\mathrm{SC}}\left(\mathrm{mA} / \mathrm{cm}^{2}\right)$ & $\mathrm{V}_{\mathrm{OC}}(\mathrm{mV})$ & $\mathrm{FF}(\%)$ & Eff $(\%)$ \\
\hline \multirow{2}{*}{ Homoepitaxial } & $\mathrm{AM} 1.5 \mathrm{~g}$ & 33.9 & 282 & 59 & 5.5 \\
\hline & 44-sun AM1.5d & 1357 & 387 & 68 & 8.9 \\
\hline \multirow{2}{*}{$\mathrm{IMF}$} & AM1.5g & 29.9 & 108 & 33 & 1.0 \\
\hline & 44-sun AM1.5d & 1196 & 291 & 52 & 4.5 \\
\hline
\end{tabular}

nation) to 1.0 (quasi-neutral region, QNR, recombination) at $\sim 3$ suns, or about $320 \mathrm{mV} \mathrm{V}_{\text {OC }}$. This indicated that only a small increase in solar flux was needed to push the cell towards QNR recombination. In contrast, this transition occurred in the IMF cell at $\sim 26$ suns, or $\sim 270 \mathrm{mV} V_{\text {OC }}$ indicating that the IMF cell had a higher number of trap states in the depletion region to fill before it became QNR-limited.

Threading dislocations were the suspected reason for the large difference in MCDL and $\mathrm{V}_{\mathrm{OC}}$ between control and IMF cells. A simple model by Yamaguchi et al. relates MCDL to TDD, ${ }^{20}$

$$
\mathrm{TDD}=4 /\left[\pi^{3}(\mathrm{MCDL})^{2}\right],
$$

where the MCDL is assumed to be dominated by TDD. Using the simulation MCDLs, the IMF cell TDD was predicted to be at least $3 \times 10^{7} \mathrm{~cm}^{-2}$, indicating that formation of $90^{\circ}$ dislocations was not uniform and the IMF array did not fully relieve lattice-mismatch strain. If the TDD can be brought below $10^{7} \mathrm{~cm}^{-2}$, the results will be more competitive with IMM. To reduce TDD, two approaches may be taken. One is to prevent threading dislocations from forming by further IMF array optimization. The other is to cause annihilation of threading dislocations in post-IMF array growth. Practically, a combination of the two may be required to achieve a good result. In the previous report, ${ }^{13}$, the AM1.5g V OC was $121 \mathrm{mV}$ despite a lower $\mathrm{J}_{\mathrm{SC}}$ of $15.5 \mathrm{~mA} / \mathrm{cm}^{2}$. The smaller dark current and higher shunt resistance suggests lower TDD than reported here, most likely due to the thicker (500 $\mathrm{nm}$ vs. $200 \mathrm{~nm}$ ) post-IMF array buffer layer. A thick buffer of 2 or $3 \mu \mathrm{m}$ would improve performance but sacrifice the low cost of a thin buffer. However, as mentioned, the combined GaAs and GaSb lattice constants would allow for six-junction cells with a single buffer layer and thus a thick buffer approach may still be economically viable.

To evaluate sidewall passivation, dark I-V measurements were taken of devices with and without the $\mathrm{Al}_{2} \mathrm{O}_{3}$ layer. Diode parameters of ideality-of-one dark current, $J_{01}$, ideality-of-two dark current, $J_{02}$, and shunt resistance, $R_{\mathrm{Sh}}$, were fit to the double-diode equation for devices of different radius. For the control cell, $J_{02}$ and $R_{\text {Sh }}$ were dependent on device size. $\mathrm{Al}_{2} \mathrm{O}_{3}$-coated homoepitaxial devices had, on average, a factor of 5 higher $R_{\mathrm{Sh}}$ than unpassivated devices, though this was at the cost of roughly double the dark current. Analysis of $J_{02}$ and $R_{\text {Sh }}$ for differently-sized devices following the same pro-

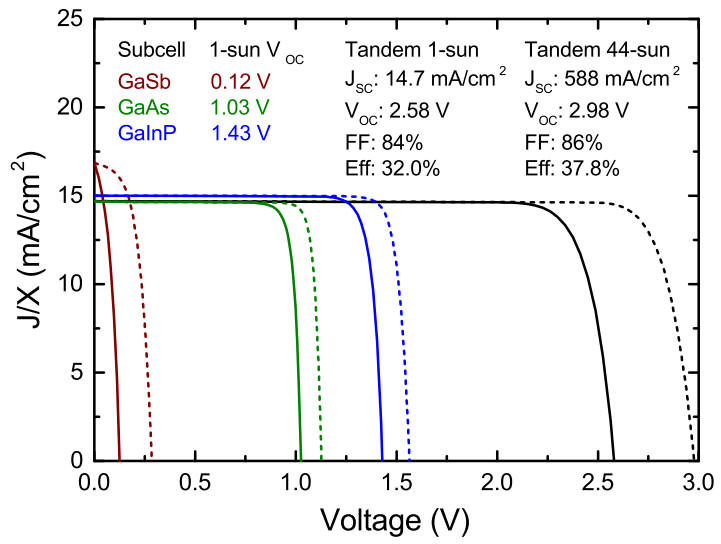

Figure 4. Simulated IMF 3-J GaInP/GaAs/GaSb solar cell with the fitted IMF GaSb lifetimes used for the GaSb bottom cell under 1 sun (solid) and 44 suns (dotted, normalized to 1-sun).

cedures of Teran et al. ${ }^{21}$ and Juang et al. ${ }^{13}$ allowed calculation of the the bulk-limited values, which were about $25 \mu \mathrm{A} / \mathrm{cm}^{2}$ and $1.6 \mathrm{k} \Omega \mathrm{cm}^{2}$, respectively. With these bulk-limited $J_{02}$ and $R_{\mathrm{Sh}}$ parameters and a $\mathrm{J}_{\mathrm{SC}}$ of $33.9 \mathrm{~mA} / \mathrm{cm}^{2}$, the double-diode model predicted AM1.5g efficiency for a large-area homoepitaxial cell with current cell design and material quality to be $7.2 \%$. A larger cell will therefore perform better, however, there were difficulties with growing large-area GaSb devices by MBE due to Ga 'spitting' and low yields as discussed elsewhere, ${ }^{22}$, although this issue could be mitigated by using a two-filament $\mathrm{Ga}$ effusion cell. Larger area $\left(1.55 \mathrm{~cm}^{2}\right)$ homoepitaxial GaSb cells grown by metalorganic chemical vapor deposition (MOCVD) have reached AM1.5g efficiencies as high as 10\%, and this should be a practical goal for a large-area MBE-grown cell with a thicker base and optimized grid shading. ${ }^{23}$ For the IMF cells, $R_{\text {Sh }}$ and $J_{02}$ did not show any trend with perimeter and the IMF devices were already bulk-limited. The best IMF $J_{02}$ and $R_{\text {Sh }}$ were $2.4 \mathrm{~mA} / \mathrm{cm}^{2}$ and $6 \Omega \mathrm{cm}^{2}$, respectively. DeMeo et al. attributed the low $R_{\mathrm{Sh}}$ of their IMF devices to possible shunt paths along threading dislocations. ${ }^{12}$

With an understanding of the current IMF material, the next step was to determine the performance of an IMF GaInP/GaAs/GaSb 3-J as it could be presently grown. A 3-J model was created with the IMF fit lifetimes from Table I and the AM1.5 I-V in Figure 4 was simulated. The GaAs subcell was simulated with typ- 
ical lifetime values to achieve a $1.03 \mathrm{~V}$ AM1.5g VOC. For GaInP, the AM1.5g V $\mathrm{OC}_{\mathrm{OC}}$ was $1.43 \mathrm{~V}$. The GaAs and GaInP subcell designs were similar to work by Takamoto et al. ${ }^{24}$ and used parameters from Algora et al. and Sato et al. ${ }^{25,26}$ As the inverted IMF cell must have its substrate removed, the gold contact on the back of the cell was also used as a mirror to increase the path length of interior photons. This allowed the IMF cell to be thinned to $0.6 \mu \mathrm{m}$ which mitigated the shorter $L$ and also improved $\mathrm{V}_{\mathrm{OC}}$. The subcell was kept current-rich to help offset the effect the low subcell FF at 1 sun. The simulated cell was $32.0 \%$ efficient, although at 1 sun this is optimistic as it assumed no bulk shunt in the IMF GaSb. At 44-suns, efficiency improved to $37.8 \%$. To determine the contribution of GaSb subcell, the GaInP/GaAs subcells were simulated as a two-junction (2-J) cell. The 2-J cell was $31.5 \%$ and $35.3 \%$ efficient under 1 sun and 44 suns, respectively. The addition of the GaSb subcell, therefore, led to absolute efficiency improvement of $0.5 \%$ at 1 sun and $2.5 \%$ at 44 suns, suggesting that the viability of IMF multijunction cells could be dependent on concentration. The industry-standard bottom subcell, the diffused-junction Ge cell, contributes more to the GaInP/GaAs system at 1 sun with a reported AM1.5g $\mathrm{V}_{\mathrm{OC}}$ (unfiltered) of 269 $\mathrm{mV}$, but the difference between it and the IMF subcell is reduced under concentration.

In conclusion, homoepitaxial and IMF GaSb solar cells were grown via MBE. The passivated homoepitaxial and IMF cells achieved 5.5\% and $1.0 \%$ efficiency under AM1.5g illumination, respectively. The IMF cell was able to recover to $4.5 \%$ efficiency under 44 -sun AM1.5d with $291 \mathrm{mV} \mathrm{V}_{\text {OC }}$, while the homoepitaxial cell achieved $8.9 \%$ efficiency under said illumination with $386 \mathrm{mV} \mathrm{V}_{\text {OC }}$. Shunting and higher non-radiative dark current were the main cause of FF and efficiency loss in IMF devices. It was found that $\mathrm{Al}_{2} \mathrm{O}_{3}$-passivated homoepitaxial cells had a factor of 5 average improvement in $R_{\text {Shunt }}$ compared to unpassivated cells, however the passivated cells were still dominated by sidewall recombination. The IMF was bulk-limited in both shunt and non-radiative recombination. A device simulator was used to fit EQE and I-V of cells and diffusion lengths were extracted. From the fit, a simulated IMF GaInP/GaAs/GaSb 3-J cell was $37.8 \%$ efficient under 44 suns, an absolute improvement over simulated GaInP/GaAs cells of $2.5 \%$.

This work was supported by grants from the National Science Foundation (ECCS-1509468) and the Bay Area Photovoltaic Consortium (DE-EE0004946 / 6096495451077).

\section{REFERENCES}

${ }^{1}$ J. F. Geisz, S. Kurtz, M. W. Wanlass, J. S. Ward, A. Duda, D. J. Friedman, J. M. Olson, W. E. McMahon, T. E. Moriarty, and J. T. Kiehl, Appl. Phys. Lett. 91, 023502 (2007).
${ }^{2}$ K. Sasaki, T. Agui, K. Nakaido, N. Takahashi, R. Onitsuka, and T. Takamoto, AIP Conf. Proc. 1556, 22 (2013).

${ }^{3}$ R. M. France, J. F. Geisz, I. García, M. A. Steiner, W. E. McMahon, D. J. Friedman, T. E. Moriarty, C. Osterwald, J. S. Ward, A. Duda, M. Young, and W. J. Olavarria, IEEE J. Photovolt 5, $432(2015)$.

${ }^{4}$ R. M. France, J. F. Geisz, M. A. Steiner, B. To, M. J. Romero, W. J. Olavarria, and R. R. King, J. Appl. Phys. 111, 103528 (2012).

${ }^{5}$ N. Karam, R. Sherif, P. Pien, G. S. Kinsey, D. D. Krut, S. Mesropian, W. Hong, A. Zakaria, M. Haddad, C. Fetzer, D. C. Law, H. Yoon, M. J. Romero, K. M. Edmondson, A. Boca, and R. King, in The 23rd European Photovoltaic Solar Energy Conference and Exhibition (Valencia, Spain, 01-05 September 2008) pp. 24-29.

${ }^{6}$ M. Stan, D. Aiken, B. Cho, A. Cornfeld, V. Ley, P. Patel, P. Sharps, and T. Varghese, J. Cryst. Growth 312, 1370 (2010). ${ }^{7}$ S. H. Huang, G. Balakrishnan, A. Khoshakhlagh, A. Jallipalli, L. R. Dawson, and D. L. Huffaker, Appl. Phys. Lett. 88, 131911 (2006).

${ }^{8}$ A. Jallipalli, G. Balakrishnan, S. H. Huang, A. Khoshakhlagh, L. R. Dawson, and D. L. Huffaker, J. Cryst. Growth 303, 449 (2007).

${ }^{9} \mathrm{M}$. Woodhouse and A. Goodrich, "Manufacturing Cost Analysis Relevant to Single-and Dual-Junction Photovoltaic Cells Fabricated with III-Vs and III-Vs Grown on Czochralski Silicon," Tech. Rep. NREL/PR-6A20-60126 (NREL, Golden, CO, 2014).

${ }^{10}$ C. J. Reyner, J. Wang, K. Nunna, A. Lin, B. Liang, M. S. Goorsky, and D. L. Huffaker, Appl. Phys. Lett. 99, 231906 (2011).

${ }^{11}$ K. C. Nunna, S. L. Tan, C. J. Reyner, A. R. J. Marshall, B. Liang, A. Jallipalli, J. P. R. David, and D. L. Huffaker, IEEE Photon. Technol. Lett. 24, 218 (2012).

${ }^{12}$ D. DeMeo, C. Shemelya, C. Downs, A. Licht, E. S. Magden, T. Rotter, C. Dhital, S. Wilson, G. Balakrishnan, and T. E. Vandervelde, J. Electron. Mater. 43, 902 (2014).

${ }^{13}$ B.-C. Juang, R. B. Laghumavarapu, B. J. Foggo, P. J. Simmonds, A. Lin, B. Liang, and D. L. Huffaker, Appl. Phys. Lett. 106, 111101 (2015).

${ }^{14}$ G. Stollwerck, O. V. Sulima, and A. Bett, IEEE Trans. Electron Devices 47, 448 (2000).

${ }^{15} \mathrm{~S}$. Huang, G. Balakrishnan, and D. L. Huffaker, J. Appl. Phys. 105, 103104 (2009)

${ }^{16}$ O. Salihoglu, A. Muti, K. Kutluer, T. Tansel, R. Turan, C. Kocabas, and A. Aydinli, J. Appl. Phys. 111, 074509 (2012).

${ }^{17}$ A. Nainani, T. Irisawa, Z. Yuan, B. R. Bennett, J. B. Boos, Y. Nishi, and K. C. Saraswat, IEEE Trans. Electron Devices 58, 3407 (2011).

${ }^{18}$ O. V. Sulima and A. W. Bett, Sol. Energ. Mat. Sol. Cells PVSEC 11 - Part II, 66, 533 (2001).

${ }^{19}$ E. J. Renteria, A. Mansoori, S. J. Addamane, D. M. Shima, C. P. Hains, and G. Balakrishnan, in IEEE 43rd Photovoltaic Specialists Conference (Portland, OR, 05-10 June 2016) pp. 2310-2312. ${ }^{20} \mathrm{M}$. Yamaguchi and C. Amano, J. Appl. Phys. 58, 3601 (1985).

${ }^{21}$ A. S. Teran, E. Moon, W. Lim, G. Kim, I. Lee, D. Blaauw, and J. D. Phillips, IEEE Trans. Electron Devices 63, 2820 (2016).

${ }^{22}$ O. S. Romero, A. A. Aragon, N. Rahimi, D. Shima, S. Addamane, T. J. Rotter, S. D. Mukherjee, L. R. Dawson, L. F. Lester, and G. Balakrishnan, J. Electron. Mater. 43, 926 (2014).

${ }^{23} \mathrm{~T}$. Schlegl, GaSb-Photovoltaikzellen für die Thermophotovoltaik, PhD Dissertation, Universität Regensburg (2006).

${ }^{24}$ T. Takamoto, E. Ikeda, H. Kurita, M. Ohmori, M. Yamaguchi, and M.-J. Yang, Jpn. J. Appl. Phys. 36, 6215 (1997).

${ }^{25}$ C. Algora and V. D ̃̂naz, Solid-State Electron. 41, 1787 (1997).

${ }^{26}$ S.-i. Sato, T. Ohshima, and M. Imaizumi, J. Appl. Phys. 105, 044504 (2009). 